\title{
Restless legs syndrome and cancer: an analysis in three independent studies
}

\author{
*Correspondence: fuhs@uni-muenster.de

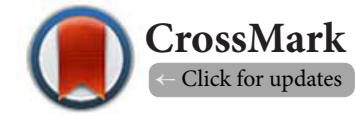 \\ 'Institute of Epidemiology and Social Medicine, University of Muenster, Germany. \\ 2Institute for Community Medicine, University of Greifswald, Germany. \\ ${ }^{3}$ Department of Neurology, Inselspital, Universitätsspital Bern, Bern, Switzerland. \\ ${ }^{4}$ Robert Koch-Institute, Berlin, Germany.
}

Andrea Fuhs ${ }^{*}$, Dunya Bentama ${ }^{1}$, Wolfgang Hoffmann², Henry Völzke², Johannes Mathis ${ }^{3}$, Klaus Kraywinkel ${ }^{4}$ and Klaus Berger ${ }^{1}$

\begin{abstract}
We report results from three independently conducted studies on the prevalence of cancer in restless legs syndrome (RLS) cases and non RLS cases. Already in 1955 Ekbom observed RLS in patients with subsequently detected cancer. Since then only three case reports and one article assessed the relationship between RLS and cancer patients undergoing chemotherapy. The observed proportion of RLS in these cancer patients (18.3\%) was about twice as high as in general population studies. Two of our studies were general population based studies (Dortmund Health Study (DHS); Study of Health in Pomerania (SHIP)) and one was performed among members of the German and Swiss RLS patient organizations (Course of Restless Legs Syndrome-Study (COR-S)). Additionally we used data from the population based, regional cancer registry of the Muenster district for comparisons. Our data show that in all three studies the prevalence of cancer was higher in RLS cases than in non cases for both genders. In two of the studies the increased risk was in part explained by age. The data of the COR-Study revealed a statistically significant higher risk for cancer in RLS subjects compared to the population based data of the regional cancer registry of Muenster. Our results suggest a higher proportion of cancer among RLS cases compared to individuals without RLS. Given an RLS prevalence of about 5 to 10 percent in the general population, a need to rule out cancer in patients with a new onset of RLS, especially among the elderly patients is important.
\end{abstract}

Keywords: Restless legs syndrome, cancer, prevalence, epidemiology

\section{Introduction}

Restless legs syndrome (RLS) is a common sleep disorder with a prevalence of $5 \%$ to $10 \%$ in the general population of Western countries [1-4]. Applying the four minimal criteria [5,6] published by the International RLS study group (IRLSSG) studies found an increasing prevalence with age $[1,7]$ and women being approximately twice as often affected as men $[2,8,9]$. In 1955 Karl Axel Ekbom was the first to report a finding of RLS in patients with anemia [10], sometimes preceding the definitive diagnosis of cancer. Cancer prevalence also increases with age. For many types, cancer incidence and mortality is higher in men than in women [11]. However, due to a better survival of women [12], their overall prevalence of cancer is higher [13].

Due to the demographic change with a growing number of older people, both diseases will gain importance. Although there are a number of cross sectional studies reporting higher prevalences of non-cancer conditions, such as diabetes, an increased body mass index $[2,7]$ and cardiovascular risk factors or diseases $[\mathbf{1}, \mathbf{1 4}]$ in RLS cases compared to non cases, cancer prevalence in RLS patients, has not yet been studied in a similar comprehensive approach. Up to now only two further case reports $[15,16]$ and a recent study that assessed the prevalence of restless legs syndrome in cancer patients undergoing chemotherapy are published [17]. The aim of our analysis was to evaluate the prevalence of cancer in individuals with and without RLS in three large independent studies in Germany.

\section{Materials and methods}

Data from three studies, independently conducted in Germany between 2002 and 2007, were used. Two of them were general population based epidemiologic studies the third one was performed among members of the German and Swiss RLS 
Fuhs et al. Epidemiology Reports 2014,

http://www.hoajonline.com/journals/pdf/2054-9911-2-4.pdf

doi: $10.7243 / 2054-9911-2-4$

patient organizations.

The Dortmund Health Study (DHS) [18] was conducted in the city of Dortmund in the western part of Germany. For examinations and interviews, a random sample from the respective population register, stratified by age and gender, was drawn. 3820 individuals, aged $25-75$ years were invited of whom 395 persons were not eligible due to death, moving or lack of sufficient knowledge of the German language to sign informal consent. Baseline assessment was done in 2003 and 2004. The initial response rate was 66.9\%, yielding 2291 participants. If a personal participation in the study centre was not possible, a questionnaire with a subset of otherwise identical questions was mailed to the participants. Due to reduced space available in the questionnaire, RLS criteria assessment was restricted to interview participants only. Thus, for the purpose of this analysis, only data of participants attending the personal interview at the study centre $(n=1312)$ were included.

The Study of Health in Pomerania (SHIP) [2], a populationbased study in the north-eastern part of Germany, was started by the University of Greifswald in 1997. Participants aged 2079 years, were drawn randomly from the regional population registration offices, stratified by age and gender. The baseline assessment (SHIP) was done between 1997 and 2000 with a baseline response of $68.8 \%$, yielding 4310 participants. The first follow-up after 5 years, conducted between 2002 and 2006 (SHIP-1) included a total of 3300 individuals (follow-up response rate $83.6 \%$ ) aged $25-88$ years. We used the data from this first follow-up for the analysis.

The Course of Restless Legs Syndrome-Study (COR-S) was started in 2007. All 4385 members of the German RLS patient organisation (RLS e.V. Deutsche Restless Legs Vereinigung) and 633 members of the Swiss patient organisation (Schweizerische Restless Legs Selbsthilfegruppe) were once contacted and invited to participate in the study. 2562 members of the German association (response proportion 58.4\%), and 254 members of the Swiss patient organisation (response proportion $40.1 \%$ ) accepted the invitation and were recruited into the study. 65 individuals became ineligible in the short period of time between invitation and questionnaire due to death, delayed refusal or moving. Thus, the COR-Study population included 2751 individuals, aged 26-96 years with an overall participant response of $56.1 \%$. 168 of the 2510 German participants had undergone a standardized, detailed diagnostic work up in one of five specialized RLS centers. Inclusion of these participants enabled the definition of a group with a diagnostic 'gold standard'.

Since the COR-Study is conducted among RLS cases only, we used data from the population based, regional cancer registry of the Muenster district (Epidemiologisches Krebsregister NRW $\mathrm{gGmbH}$ ) for comparisons. Being attached to the International Agency for Research on Cancer (IARC), the cancer registry collects data on the frequency and distribution of cancer in the area. For comparisons the 10-year prevalence of cancer was used, including all subjects who were diagnosed with cancer and survived during the period from 1994 to 2004 in the district of Muenster. These data were either collected by pathologists or had been reported by the treating hospital. In DHS and SHIP RLS was diagnosed according to the minimal criteria published 1995 by the IRLSSG. Face to face interviews in both studies included identical questions for RLS that had been validated against physician classification [19] and been used in identical form before [3]. The three questions included: 1) Do you have sensory discomfort like tingling, crawling with ants or pain in the legs associated with an urge to move? 2). Do these symptoms occur at rest i.e., while sitting down or falling asleep, and do they improve by moving? 3) Are these symptoms worse in the evening or at night, compared with the morning? The answer categories were in all cases 'Yes', 'No' or 'I don't know'. To be diagnosed as RLS positive, participants had to answer all three questions with 'Yes'. In addition symptom frequency was assessed in both studies. Only DHS participants were additionally asked if a physician had ever diagnosed RLS. These individuals $(n=19)$ were categorized as RLS positive, even if they did not fulfill the minimal criteria at the time of the interview. Data on the self-reported history of cancer, including the type of cancer, frequency of cardiovascular risk factors and disorders and other comorbidities were collected in DHS and SHIP-1.

The baseline questionnaire of the COR-Study covered questions about medical history, diagnostic methods, duration of RLS symptoms and socio-demographic data. Other comorbidities including cancer were assessed. In case of a positive cancer history, additional information about the type of cancer, the year of diagnosis and resulting therapies were collected. No validation of the participant's self-report of cancer was done. However, in case of contradictory information, e.g., breast cancer in men, additional information was collected by telephone and the corrected data were used. With regard to the international classification of diseases, $10^{\text {th }}$ revision (ICD-10) all cancer types were included except the non melanoma skin cancer (ICD C44). Participants with this type of cancer were not coded as cancer cases.

Only in the COR-Study the German version of the International RLS study group severity scale (IRLS) was used as a validated scale [20] to assess the severity of RLS. Ethics statement:The study protocol of the COR-Study was approved by the local ethics committee of the Medical Faculty at the University of Muenster.

\section{Statistical analysis}

All analyses were done separately in the three studies. Differences in cancer prevalences between RLS positive and RLS negative individuals in each study were compared using Chi-square test or Fischer's exact test if the cell number was 5 or less. Logistic regression was used to determine unadjusted as well as age and gender adjusted odds ratios for cancer in each study. To assess age adjusted odds ratios comparing 
Fuhs et al. Epidemiology Reports 2014,

data from the cancer registry and the COR-Study, we used the Mantel-Haenszel method. All analyses were done with STATA 9.0 (StatCorp LP, College Station, TX, USA).

\section{Results}

In total 7363 adults participated in these three independent studies, 2751 in the COR-Study, 1312 in DHS and 3300 in SHIP-1. Table 1 summarizes the characteristics of all participants stratified by study. Due to different age inclusion criteria, age ranges of the recruited participants differed between studies. Mean age was highest in the COR-Study with 65.9 years. $71.6 \%$ of the participants in the COR-Study and about $50 \%$ in the other two studies were women. The prevalence of RLS in DHS was $8.8 \%$ (10.2\% in women and $7.2 \%$ in men) and $10.5 \%$ in SHIP-1 (13.6\% in women and $7.2 \%$ in men). $4.3 \%$ of the participants of DHS reported a diagnosis of cancer, $5.2 \%$ of the women and 3.3\% of the men. In SHIP-1 overall $4.7 \%$ self-reported a cancer diagnosis, $4.4 \%$ of the female and $4.9 \%$ of the male participants. In contrast, $12.5 \%$ of the COR-Study participants reported cancer, $12.1 \%$ of the women and $13.4 \%$ of the men.

Table 1. Characteristics of the participants in the three studies (DHS, SHIP-1 and COR-Study).

\begin{tabular}{|c|c|c|c|}
\hline & $\begin{array}{l}\text { Dortmund } \\
\text { DHS } \\
\mathrm{n}=1312\end{array}$ & $\begin{array}{l}\text { Pomerania } \\
\text { SHIP-1 } \\
\mathrm{n}=3300\end{array}$ & $\begin{array}{l}\text { Course of } \\
\text { RLS Study } \\
\text { COR-Study } \\
\mathrm{n}=\mathbf{2 7 5 1} \\
\end{array}$ \\
\hline Mean age (range), years & $52.1(25-74)$ & $54.5(25-88)$ & $65.9(27-96)$ \\
\hline Mean age women (range), years & $51.1(25-74)$ & $53.5(25-88)$ & $65.5(29-96)$ \\
\hline Mean age men (range), years & $53.3(25-74)$ & $55.5(25-86)$ & $66.9(27-94)$ \\
\hline Women, \% & 52.9 & 51.9 & 71.6 \\
\hline Prevalence of RLS, \% & 8.8 & 10.5 & 100.0 \\
\hline Women, \% & 10.2 & 13.6 & 100.0 \\
\hline Men, \% & 7.1 & 7.2 & 100.0 \\
\hline Prevalence of cancer ${ }^{1}, \%$ & 4.3 & 4.7 & 12.5 \\
\hline Women, \% & 5.2 & 4.4 & 12.1 \\
\hline Men, \% & 3.3 & 4.9 & 13.4 \\
\hline $\begin{array}{l}\text { Known diagnosis of } \\
\text { hypertension }{ }^{2}, \%\end{array}$ & 35.2 & 50.4 & 46.4 \\
\hline Known diagnosis of diabetes ${ }^{2}, \%$ & 7.6 & 11.2 & 10.7 \\
\hline $\begin{array}{l}\text { History of myocardial } \\
\text { infarction }^{2}, \%\end{array}$ & 3.7 & 4.3 & 5.0 \\
\hline Body mass index $\geq 30^{3}, \%$ & 26.4 & 30.4 & 18.8 \\
\hline $\begin{array}{l}{ }^{1} \text { excluding non-melanoma ski } \\
{ }^{2} \text { self-reported physician diagn } \\
\text { 3based on self-reported (COR- } \\
\text { (DHS and SHIP1) height and }\end{array}$ & $\begin{array}{l}\text { cancer } \\
\text { is } \\
\text { tudy) or } \\
\text { eight }\end{array}$ & sured & \\
\hline
\end{tabular}

Tables 2 and $\mathbf{3}$ provide the cancer prevalences according to age and gender separately in the three studies. A consistent higher prevalence of cancer in both genders and all age

Table 2. Prevalence of cancer in male RLS cases and non cases according to age group and study.

\begin{tabular}{|c|c|c|c|c|c|c|}
\hline \multirow[b]{2}{*}{ Age group } & \multicolumn{2}{|c|}{ DHS } & \multicolumn{2}{|c|}{ SHIP-1 } & \multirow{2}{*}{$\begin{array}{l}\text { COR- } \\
\text { Study } \\
\text { RLS+ }\end{array}$} & \multirow{2}{*}{$\begin{array}{l}\begin{array}{l}\text { Cancer } \\
\text { registry }\end{array} \\
--\end{array}$} \\
\hline & RLS+ & RLS- & RLS+ & RLS- & & \\
\hline$<34$ years, $\%$ & 33.3 & $1.3^{*}$ & 0 & 0 & 0 & 0.2 \\
\hline $35-44$ years, $\%$ & 0 & 0 & 0 & 0.8 & 0 & 0.5 \\
\hline $45-54$ years, $\%$ & 0 & 1.8 & 4.6 & 1.4 & 4.5 & $1.0^{*}$ \\
\hline $55-64$ years, $\%$ & 7.1 & 2.0 & 5.0 & 4.5 & 8.6 & $3.2^{*}$ \\
\hline $65-74$ years, $\%$ & 7.1 & 8.2 & 12.1 & 10.0 & 9.8 & 7.0 \\
\hline $75+$ years, $\%$ & -- & -- & 21.1 & 10.8 & 27.8 & $10.1^{*}$ \\
\hline TOTAL, \% & 7.0 & 3.0 & 8.7 & $4.6^{*}$ & 13.4 & $1.9^{*}$ \\
\hline $\begin{array}{l}\text { OR, unadjusted } \\
(95 \% \mathrm{CI})\end{array}$ & $2.45(0$ & $.69-8.72)$ & $2.00(1$ & $0-4.00)$ & $8.23(6$ & 64-10.13) \\
\hline $\begin{array}{l}\text { OR, age adjusted } \\
(95 \% \mathrm{CI})\end{array}$ & $1.98(0$ & $.54-7.18)$ & $1.62(0$ & 9-3.31) & $2.44(1$ & 98-3.01) \\
\hline \multicolumn{7}{|c|}{ Restricted to age group 25-74 years: } \\
\hline TOTAL, \% & 7.0 & 3.0 & 6.3 & 3.7 & 8.2 & $1.4^{*}$ \\
\hline $\begin{array}{l}\text { OR, unadjusted } \\
(95 \% \mathrm{CI})\end{array}$ & \multicolumn{2}{|c|}{$2.45(0.69-8.72)$} & \multicolumn{2}{|c|}{$1.76(0.73-4.22)$} & \multicolumn{2}{|c|}{$6.33(4.59-8.54)$} \\
\hline $\begin{array}{l}\text { OR, age adjusted } \\
(95 \% \mathrm{CI})\end{array}$ & \multicolumn{2}{|c|}{$1.98(0.54-7.18)$} & \multicolumn{2}{|c|}{$1.31(0.53-3.22)$} & \multicolumn{2}{|c|}{$1.82(1.35-2.47)$} \\
\hline
\end{tabular}

${ }^{*} \mathrm{p}<0.05$ for the comparison within the age stratum

(Chi Square Test) ${ }^{1}$ RLS prevalence in the source population

$(\mathrm{n}=1,280,314$ in 2004) unknown

Table 3. Prevalence of cancer in female RLS cases and non cases according to age group and study.

\begin{tabular}{|c|c|c|c|c|c|c|}
\hline & \multicolumn{2}{|c|}{ DHS } & \multicolumn{2}{|c|}{ SHIP-1 } & \multirow{2}{*}{$\begin{array}{l}\text { COR- } \\
\text { Study } \\
\text { RLS+ }\end{array}$} & \multirow{2}{*}{$\begin{array}{l}\text { Cancer } \\
\text { registry }\end{array}$} \\
\hline Age group & RLS+ & RLS- & RLS+ & RLS- & & \\
\hline$<34$ years, $\%$ & 0 & 0 & 11.1 & $0^{*}$ & 0 & 0.2 \\
\hline $35-44$ years, $\%$ & 6.7 & 3.1 & 2.7 & 2.4 & 5.8 & $0.8^{*}$ \\
\hline $45-54$ years, $\%$ & 8.3 & 2.1 & 0 & 4.1 & 11.0 & $2.1^{\star}$ \\
\hline $55-64$ years, $\%$ & 15.0 & 8.5 & 8.6 & $3.3^{*}$ & 4.0 & $3.8^{*}$ \\
\hline $65-74$ years, $\%$ & 11.1 & 8.8 & 7.1 & 6.4 & 11.8 & $5.1^{*}$ \\
\hline $75+$ years, $\%$ & -- & -- & 12.5 & 11.6 & 13.1 & $6.1^{\star}$ \\
\hline TOTAL, \% & 9.9 & 4.7 & 6.5 & 4.1 & 12.1 & $2.1^{*}$ \\
\hline $\begin{array}{l}\text { OR, unadjusted } \\
(95 \% \mathrm{CI})\end{array}$ & $2.24(0$ & $94-5.32)$ & $1.63(0$. & $1-2.92)$ & $6.61(5$ & $.76-7.59)$ \\
\hline $\begin{array}{l}\text { OR, age adjusted } \\
(95 \% \mathrm{CI})\end{array}$ & $1.93(0$ & $80-4.65)$ & $1.34(0$. & $4-2.42)$ & $2.97(2$ & $59-3.40)$ \\
\hline \multicolumn{7}{|c|}{ Restricted to age group 25-74 years: } \\
\hline TOTAL, \% & 9.9 & 4.7 & 5.8 & 3.3 & 11.9 & $1.6^{*}$ \\
\hline $\begin{array}{l}\text { OR, unadjusted } \\
(95 \% \mathrm{CI})\end{array}$ & \multicolumn{2}{|c|}{$2.24(0.94-5.32)$} & \multicolumn{2}{|c|}{$1.80(0.93-3.46)$} & \multicolumn{2}{|c|}{$8.33(7.14-9.72)$} \\
\hline $\begin{array}{l}\text { OR, age adjusted } \\
(95 \% \mathrm{CI})\end{array}$ & \multicolumn{2}{|c|}{$1.93(0.80-4.65)$} & \multicolumn{2}{|c|}{$1.47(0.76-2.86)$} & \multicolumn{2}{|c|}{$3.17(2.72-3.69)$} \\
\hline
\end{tabular}


Fuhs et al. Epidemiology Reports 2014,

groups for RLS sufferers was seen in the three studies. The overall probability, expressed as the prevalence odds ratio, was 8- and 6- fold higher for men and women, respectively, in the COR-Study, and roughly two-fold higher for RLS cases for both genders in DHS and SHIP-1. After adjusting for age however, this probability attenuated considerably and was no longer statistical significant in DHS and SHIP-1. For a better comparison of the three studies including the cancer registry, we set the upper age limit to 74 years (Tables $\mathbf{2}$ and $\mathbf{3}$ ) due to the exclusion of participants older than 74 years in DHS. This age restriction slightly decreased the possibility of cancer in men with RLS in SHIP-1 and COR-S, and increased the one for women in both studies. Again, only the odds ratios for the COR-Study in comparison with the cancer registry remained significant.

Table 4 summarizes the prevalences of breast and prostate cancer in the COR-Study and the cancer registry. $43.6 \%$ of all documented female cancers in the cancer registry were breast cancers and $34.0 \%$ of all male cancers were prostate cancers. The COR-Study revealed similar results for breast cancer with $42.7 \%$ of all cancer types in female participants being breast cancer, but a higher proportion of $45.7 \%$ prostate cancers in men. The likelihood of having a prostate cancer for male participants of the COR-Study was higher in comparison to male cancer cases in the cancer registry (OR 1.63,95\% CI $1.08,2.44)$. Of all COR-Study participants with a history of cancer $4.9 \%(n=17)$ suffered from more than one cancer type.

Table 4. Prevalence of cancer subtypes in the Course of RLS-Study and the cancer registry.

\begin{tabular}{lllll}
\hline & \multicolumn{2}{l}{ COR-Study } & \multicolumn{2}{l}{ Cancer registry $^{2}$} \\
\hline & $\mathbf{N}$ & $\%$ & $\mathrm{~N}$ & $\%$ \\
\hline overall cancer & 344 & 12.5 & 51167 & 1.95 \\
women, total & 239 & 12.1 & 27520 & 2.05 \\
breast & $102^{1}$ & $5.2^{1}$ & 12006 & 0.89 \\
other cancers & $147^{1}$ & $7.5^{1}$ & 15514 & 1.15 \\
men, total & 105 & 13.4 & 23647 & 1.85 \\
prostate & $48^{1}$ & $6.1^{1}$ & 8040 & 0.63 \\
other cancers & $65^{1}$ & $8.3^{1}$ & 15607 & 1.22 \\
\hline
\end{tabular}

${ }^{1}>1$ carcinoma (COR-Study $\mathrm{n}=17$

(one triple carcinoma) $=4.9 \%$ )

${ }^{2}>1$ carcinoma $\mathrm{n}$ unknown

Data from the cancer registry concerning history of more than one type of cancer were not available. In a second step we analyzed if RLS severity was related to cancer prevalence in the COR-Study. However, after adjustment for age and gender no difference in mean severity between RLS subjects with and without cancer was noted (OR 1.01, 95\% Cl 0.99, 1.02). Also, when the RLS severity score was broken down in five categories of increasing severity, the proportion of individuals with cancer in each category was not significantly different, and, thus, no trend of higher cancer prevalences with increasing RLS severity was found (ptrend $=0.13$ ).

Considering the question of the onset of cancer versus the onset of RLS, more than $73 \%$ of the COR-Study participants with cancer reported RLS symptoms before the cancer diagnosis. $21.8 \%$ had a cancer diagnosis before onset of RLS symptoms and $4.4 \%$ reported the onset of both diseases in the same year. Moreover, cancer therapy can be considered as a possible cause for the induction of RLS in participants with a primary cancer diagnosis. $39.4 \%$ of all participants with a cancer diagnosis had received radiotherapy and $27.7 \%$ had chemotherapy. $19.7 \%$ of those receiving chemotherapy, developed RLS over the course or after finishing chemotherapy. $25.0 \%$ of the subjects receiving radiotherapy, complained about RLS symptoms during or after application of the radiotherapy.

\section{Discussion}

We compared the prevalence of cancer between RLS cases and non cases in three large and independently conducted studies in Germany. The main finding of this analysis was a higher prevalence of cancer in RLS cases compared to non cases in all three studies. After stratification by gender a higher probability for cancer in RLS subjects in two of the studies was explained by age but remained in the third statistically significant. No elevated probability for breast cancer was found for female participants of the COR-Study. However, the probability for prostate cancer in men with cancer and RLS was significantly increased.

The causes of RLS are still not entirely understood. Genetic factors are supposed to play an important role in the cause of idiopathic RLS. In addition several gene loci, identified in linkage studies in RLS families [21] and genome-wide association studies (GWAS) have revealed intronic or intergenic regions of the four genes BTBD9 [22], MEIS1 and LBXCOR1/ MAP2K5 [23], which are supposed to be involved in up to $70 \%$ of all genetic RLS cases [24] and PTPRD, recently [25]. Lower serum ferritin levels are also associated with BTBD9 [22]. A potential role of these loci for the onset of cancer is unclear and has to be determined.

Prostate cancer is the most common cancer in men in Germany (Robert Koch Institute, 2008). Similar to RLS, familial aggregation of prostate cancer is known. Male relatives of affected men have a two-fold increased risk for prostate cancer, especially if the cancer diagnosis was made before age 60 years [26]. Lifestyle and environmental related risk factors for prostate cancer have not been found yet. Similar to RLS prostate cancer is genetically complex and predisposition may be passed on through multiple common low-penetrance alleles in combination with lifestyle or environmental risk factors [27]. Taking recent findings from genetic and epidemiologic studies into account, the question arises [28] if prostate cancer and RLS share more common biological pathways than only low serum ferritin levels and/or anemia. 
Fuhs et al. Epidemiology Reports 2014,

Knowledge on risk factors for the onset of RLS from prospective studies is still sparse. However, several RLS risk factors are hypothesized in cross-sectional studies, such as diabetes, an increased body mass index $[2,7]$, hypertension and heart problems [1].

In the COR-Study two thirds of the participants with cancer developed RLS before their cancer was diagnosed. Chemoand radiotherapy seemed to have no influence on the onset of RLS. Three prior articles have discussed the possibility of an association between cancer and RLS. Ekbom [10], Brocklehurst [15], and Parish [16] presented case reports in which RLS had been a symptom of a still unknown malignant disease, due to decreased serum ferritin levels caused by occult bleeding in the gut or bladder. Thus, so called secondary RLS cases, especially, should carefully be evaluated for an early stage cancer. In these cases treatment of the respective cancer would be a causal therapy. Ostacoli [17], in contrast, assessed the prevalence of RLS in cancer patients while undergoing chemotherapy. RLS patients were identified by a screening questionnaire fulfilling the minimal criteria for RLS, followed by a structured interview with a sleep specialist to confirm the diagnosis of RLS. They reported a prevalence of RLS of $18.3 \%$ in these patients, however, did not assess the length of time participants had already suffered from RLS symptoms. Thus, information about the onset of RLS and the time sequence between RLS and cancer is not known. It can be a challenge to disentangle the causal pathway and time sequence of answered of both conditions in an individual. RLS could be second to cancer onset, especially in cancer patients receiving chemotherapy. RLS could co-occur shortly before or at cancer symptom onset due to shared pathophysiologic pathways such as anemia or renal failure. The pathophysiology of RLS is not yet completely understood. Iron deficiency as well as dopamine dysregulation have shown to play an important role on the onset of the disease [29]. Finally, it cannot be excluded that RLS is a predictor of some later cancer types, e.g., due to common genetic susceptibility. The frequency of most cancer types as well as of RLS increases with age. Given the demographic changes in most Western countries the number of individuals affected by either or both conditions will sharply increase over the next decades.

Strengths of our analysis are the inclusion of three independent large studies enabling to compare the RLS-cancer relationship across different study settings and regions. We used a standardized assessment of RLS case-status according to the minimal criteria of the IRLSSG in two population studies. A limitation of this work is that assessment of RLS symptoms and the diagnosis of cancer were based on self-reports and we can not exclude a misclassification of both conditions. However, the RLS classification had prior been validated against physician rating [19] and showed a good reliability. Also the validity of self reported cancer diagnoses is high due to their perceived severity in most cases. Since the COR-Study included cases only we used data of a well established cancer registry, as controls. The register covered a 10-year prevalence only, and might underestimate the prevalence for all types of cancer compared to the lifetime assessment done in the other studies. The unknown proportion of RLS cases in the cancer registry might further cause a slight underestimation of the RLS cancer risk. DHS did not include the age group $75+$, in which the highest prevalence of cancer is generally observed.

In summary our comparisons of the prevalence of cancer in RLS cases and non-cases show the need to study the relationship between RLS and cancer in detail. Clinically, our results emphasize the necessity to rule out cancer in patients with a new onset of RLS symptoms, especially among elderly patients. Replication of these findings in prospective studies are required. From a pathophysiological aspect the question arises if both conditions share biological pathways in their development which may ultimately provide clues for causal therapy approaches. From an epidemiologic perspective prospective cohort studies are necessary to disentangle the time sequence between both diseases, however, these need large sample sizes due to the low cancer incidence under the age of 60 years.

\section{Competing interests}

The authors declare that they have no competing interests.

Authors' contributions

\begin{tabular}{|l|c|c|c|c|c|c|c|}
\hline Authors' contributions & AF & DB & WH & HV & JM & KK & KB \\
\hline Research concept and design & -- & -- & -- & $\checkmark$ & -- & -- & $\checkmark$ \\
\hline Collection and/or assembly of data & $\checkmark$ & $\checkmark$ & -- & $\checkmark$ & -- & $\checkmark$ & $\checkmark$ \\
\hline Data analysis and interpretation & $\checkmark$ & $\checkmark$ & $\checkmark$ & -- & $\checkmark$ & $\checkmark$ & $\checkmark$ \\
\hline Writing the article & $\checkmark$ & -- & -- & -- & -- & -- & -- \\
\hline Critical revision of the article & $\checkmark$ & $\checkmark$ & $\checkmark$ & $\checkmark$ & $\checkmark$ & $\checkmark$ & $\checkmark$ \\
\hline Final approval of article & $\checkmark$ & $\checkmark$ & $\checkmark$ & $\checkmark$ & $\checkmark$ & $\checkmark$ & $\checkmark$ \\
\hline Statistical analysis & $\checkmark$ & -- & -- & -- & -- & $\checkmark$ & $\checkmark$ \\
\hline
\end{tabular}

\section{Acknowledgement}

We are indebted to the members of the German and Swiss patient organisations for participating and supporting this study. The COR-Study was supported by unrestricted grants to the University of Muenster from the German Restless Legs Society (RLS e.V. Deutsche Restless Legs Vereinigung) and Boeringer Ingelheim Pharma, Mundipharma Research, Roche Pharma, Neurobiotec and UCB (Schwarz Pharma). SHIP was part of the Community Medicine Research Net of the University of Greifswald (available at: http://www.medizin.uni-greifswald.de/cm) and was funded by grant ZZ9603 from the Federal Ministry of Education and Research, Berlin, and the Ministers of Cultural and Social Affairs of the Federal State of Mecklenburg-West Pomerania, Schwerin. DHS was supported by the German Migraine \& Headache Society and by unrestricted grants of equal share from Almirall, Astra Zeneca, Berlin Chemie, Boehringer, Boots Health Care, Glaxo-Smith-Kline, Janssen Cilag, McNeil Pharma, MSD Sharp \& Dohme and Pfizer to the University of Muenster.

\section{Publication history}

Editor: Randall E. Harris, The Ohio State University, USA.

Received: 04-May-2014 Final Revised: 14-Jun-2014

Accepted: 26-Jun-2014 Published: 08-Jul-2014 
Fuhs et al. Epidemiology Reports 2014,

\section{References}

1. Ulfberg J, Nystrom B, Carter N and Edling C. Prevalence of restless legs syndrome among men aged 18 to 64 years: an association with somatic disease and neuropsychiatric symptoms. Mov Disord. 2001; 16:1159-63. | Article | PubMed

2. Berger K, Luedemann J, Trenkwalder C, John U and Kessler C. Sex and the risk of restless legs syndrome in the general population. Arch Intern Med. 2004; 164:196-202. | Article | PubMed

3. Rothdach AJ, Trenkwalder C, Haberstock J, Keil U and Berger K. Prevalence and risk factors of RLS in an elderly population: the MEMO study. Memory and Morbidity in Augsburg Elderly. Neurology. 2000; 54:1064-8. | Article | PubMed

4. Hening W, Walters AS, Allen RP, Montplaisir J, Myers A and Ferini-Strambi L. Impact, diagnosis and treatment of restless legs syndrome (RLS) in a primary care population: the REST (RLS epidemiology, symptoms, and treatment) primary care study. Sleep Med. 2004; 5:237-46. | Article | PubMed

5. Walters AS. Toward a better definition of the restless legs syndrome. The International Restless Legs Syndrome Study Group. Mov Disord. 1995; 10:634-42. | Article | PubMed

6. Allen RP, Picchietti D, Hening WA, Trenkwalder C, Walters AS and Montplaisi J. Restless legs syndrome: diagnostic criteria, special considerations, and epidemiology. A report from the restless legs syndrome diagnosis and epidemiology workshop at the National Institutes of Health. Sleep Med. 2003; 4:101-19. | Article | PubMed

7. Phillips B, Young T, Finn L, Asher K, Hening WA and Purvis C. Epidemiology of restless legs symptoms in adults. Arch Intern Med. 2000; 160:2137-41. | Article | PubMed

8. Hogl B, Kiechl S, Willeit J, Saletu M, Frauscher B, Seppi K, Muller J, Rungger $G$, Gasperi $A$, Wenning $G$ and Poewe $W$. Restless legs syndrome: a community-based study of prevalence, severity, and risk factors. Neurology. 2005; 64:1920-4. | Article | PubMed

9. Allen RP, Walters AS, Montplaisir J, Hening W, Myers A, Bell TJ and Ferini-Strambi L. Restless legs syndrome prevalence and impact: REST general population study. Arch Intern Med. 2005; 165:1286-92. | Article I PubMed

10. Ekbom KA. [Restless legs as an early symptom of cancer]. Sven Lakartidn. 1955; 52:1875-83. | PubMed

11. Parkin DM, Bray F, Ferlay J and Pisani P. Estimating the world cancer burden: Globocan 2000. Int J Cancer. 2001; 94:153-6. | Article I PubMed

12. Sant M, Aareleid T, Berrino F, Bielska Lasota M, Carli PM, Faivre J, Grosclaude P, Hedelin G, Matsuda T, Moller H, Moller T, Verdecchia A, Capocaccia R, Gatta G, Micheli A, Santaquilani M, Roazzi P and Lisi D. EUROCARE-3: survival of cancer patients diagnosed 1990-94--results and commentary. Ann Oncol. 2003; 14 Suppl 5:v61-118. | Article | PubMed

13. Micheli A, Mugno E, Krogh V, Quinn MJ, Coleman M, Hakulinen T, Gatta $G$, Berrino $F$ and Capocaccia R. Cancer prevalence in European registry areas. Ann Oncol. 2002; 13:840-65. | Article | PubMed

14. Berger $\mathrm{K}$ and Kurth T. RLS epidemiology--frequencies, risk factors and methods in population studies. Mov Disord. 2007; 22 Suppl 18:S420-3. | Article | PubMed

15. Brocklehurst J. Restless legs syndrome as a presenting symptom in malignant disease. Age Ageing. 2003; 32:234. | Article | PubMed

16. Parish JM. "I can't sleep at night" an unusual case of insomnia. J Clin Sleep Med. 2005; 1:305-8. I PubMed

17. Ostacoli L, Saini A, Ferini-Strambi L, Castronovo V, Sguazzotti E, Picci RL, Toje M, Gorzegno G, Capogna S, Dongiovanni V, Dogliotti L, Furlan $P M$ and Berruti A. Restless legs syndrome and its relationship with anxiety, depression, and quality of life in cancer patients undergoing chemotherapy. Qual Life Res. 2010; 19:531-7. | Article I PubMed

18. Happe S, Vennemann M, Evers S and Berger K. Treatment wish of individuals with known and unknown restless legs syndrome in the community. J Neurol. 2008; 255:1365-71. | Article | PubMed

19. Berger K, von Eckardstein A, Trenkwalder C, Rothdach A, Junker R and
Weiland SK. Iron metabolism and the risk of restless legs syndrome in an elderly general population--the MEMO-Study. J Neurol. 2002; 249:1195-9. | Article | PubMed

20. Walters AS, LeBrocq C, Dhar A, Hening W, Rosen R, Allen RP and Trenkwalder $C$. Validation of the International Restless Legs Syndrome Study Group rating scale for restless legs syndrome. Sleep Med. 2003; 4:121-32. | Article | PubMed

21. Trenkwalder C, Hogl B and Winkelmann J. Recent advances in the diagnosis, genetics and treatment of restless legs syndrome. J Neurol. 2009; 256:539-53. | Article | PubMed

22. Stefansson $H$, Rye DB, Hicks A, Petursson $H$, Ingason $A$, Thorgeirsson TE, Palsson S, Sigmundsson T, Sigurdsson AP, Eiriksdottir I, Soebech E, Bliwise D, Beck JM, Rosen A, Waddy S, Trotti LM, Iranzo A, Thambisetty M, Hardarson GA, Kristjansson K, Gudmundsson LJ, Thorsteinsdottir U, Kong A, Gulcher JR, Gudbjartsson D and Stefansson K. A genetic risk factor for periodic limb movements in sleep. N Engl J Med. 2007; 357:639-47. I Article | PubMed

23. Winkelmann J, Schormair B, Lichtner P, Ripke S, Xiong L, Jalilzadeh S, Fulda S, Putz B, Eckstein G and Hauk S et al. Genome-wide association study of restless legs syndrome identifies common variants in three genomic regions. Nat Genet. 2007; 39:1000-6. | Article | PubMed

24. Satija P and Ondo WG. Restless legs syndrome: pathophysiology, diagnosis and treatment. CNS Drugs. 2008; 22:497-518. | Article | PubMed

25. Schormair B, Kemlink D, Roeske D, Eckstein G, Xiong L, Lichtner P, Ripke $\mathrm{S}$, Trenkwalder C, Zimprich A and Stiasny-Kolster K et al. PTPRD (protein tyrosine phosphatase receptor type delta) is associated with restless legs syndrome. Nat Genet. 2008; 40:946-8. | Article | PubMed

26. Johns $L E$ and Houlston RS. A systematic review and meta-analysis of familial prostate cancer risk. BJU Int. 2003; 91:789-94. | Article | PubMed

27. MacInnis RJ, Antoniou AC, Eeles RA, Severi G, Guy M, McGuffog L, Hall AL, O'Brien LT, Wilkinson RA and Dearnaley DP et al. Prostate cancer segregation analyses using $\mathbf{4 3 9 0}$ families from UK and Australian population-based studies. Genet Epidemiol. 2010; 34:42-50. | Article | PubMed

28. Gudmundsson J, Sulem P, Steinthorsdottir V, Bergthorsson JT, Thorleifsson G, Manolescu A, Rafnar T, Gudbjartsson D, Agnarsson BA, Baker A, Sigurdsson A and Benediktsdottir KR et al. Two variants on chromosome 17 confer prostate cancer risk, and the one in TCF2 protects against type 2 diabetes. Nat Genet. 2007; 39:977-83. | Article | PubMed

29. Dauvilliers $Y$ and Winkelmann J. Restless legs syndrome: update on pathogenesis. Curr Opin Pulm Med. 2013; 19:594-600. | Article | PubMed

\section{Citation:}

Fuhs A, Bentama D, Hoffmann W, Völzke H, Mathis J, Kraywinkel $\mathrm{K}$ and Berger $\mathrm{K}$. Restless legs syndrome and cancer: an analysis in three independent studies. Epidemiol Rep. 2014; 2:4.

http://dx.doi.org/10.7243/2054-9911-2-4 